\title{
도시가스 일일수요의 단기예측
}

\author{
박진수 ${ }^{1} \cdot$ 김윤배 $^{2^{\dagger}} \cdot$ 정철우 $^{2}$ \\ ${ }^{1}$ 용인대학교 경영정보학과 / ${ }^{2}$ 성균관대학교 시스템경영공학과
}

\section{Short-Term Forecasting of City Gas Daily Demand}

\author{
Jinsoo Park ${ }^{1} \cdot$ Yun Bae Kim$^{2} \cdot$ Chul Woo Jung ${ }^{2}$ \\ ${ }^{1}$ Department of Management Information Systems, Yong In University \\ ${ }^{2}$ Department of Systems Management Engineering, Sungkyunkwan University
}

\begin{abstract}
Korea gas corporation (KOGAS) is responsible for the whole sale of natural gas in the domestic market. It is important to forecast the daily demand of city gas for supply and demand control, and delivery management. Since there is the autoregressive characteristic in the daily gas demand, we introduce a modified autoregressive model as the first step. The daily gas demand also has a close connection with the outdoor temperature. Accordingly, our second proposed model is a temperature-based model. Those two models, however, do not meet the requirement for forecasting performances. To produce acceptable forecasting performances, we develop a weighted average model which compounds the autoregressive model and the temperature model. To examine our proposed methods, the forecasting results are provided. We confirm that our method can forecast the daily city gas demand accurately with reasonable performances.
\end{abstract}

Keywords: City Gas Daily Demand, Autoregressive Model, Temperature-Based Model, Factor by day of the Week, Weighted Average Model

\section{1. 서 론}

한국가스공사 (Korea Gas Corporation, KOGAS)는 해외 원산지 에서 천연가스를 액체 상태의 액화천연가스(liquid natural gas, $\mathrm{LNG}$ )로 도입하여 이를 다시 기화시킨 후 발전소 또는 일반 도 시가스회사에 공급한다. 이 중 도시가스는 대부분 가정용 혹 은 상업용으로 사용된다. 가정용 도시가스는 2010년 말 기준 으로 국내 보급률이 $72 \%$ 에 달할 만큼 우리나라 에너지 사용에 큰 비중을 차지하고 있다(출처 : 한국가스공사 $\mathrm{LNG}$ 판매 통 계). KOGAS는 일일 총 공급량을 근거로 생산기지별 송출량 조절 및 전국 주 배관망의 계통운영을 시행하기 때문에 도시 가스의 일일 총 수요에 대한 예측은 매우 중요한 사안이다.

에너지 수요예측 연구 분야는 전력수요, 지역난방 열수요, 가스수요 등으로 구분할 수 있다. 이 중 전력수요 예측에 관한 연구는 매우 다양한 형태로 활발히 이루어지고 있다(Hippert $e t$ al., 2001; Ling et al., 2003; Baczyński and Parol, 2004; Chen et al., 2010; Amina et al., 2012). 또한 지역난방에 의한 열 보급이 증가함에 따라 이에 대한 수요예측 모형의 연구 또한 활발히 진행되고 있다(Dotzauer, 2002; Kvarnsöm et al., 2006; Park et al., 2009; Chramcov, 2010; Baek and Han, 2011; Song et al., 2011). 가스의 경우는 천연가스에 대한 예측 연구가 대부분이 다(Brown and Matin, 1996; Sarak and Satman, 2003; Azadeh et al., 2010; Erdogdu, 2010; Li et al., 2011; Wadud et al., 2011). 최 근 Kim et al.(2011)은 도시가스용 천연가스의 소비함수를 실 증분석과 함께 소개한 바 있다.

기존 문헌 연구를 종합해보면 에너지 수요에 영향을 미치는 요인으로는 추세적 요인, 기온, 요일 등을 들 수 있다. 물론 전 력 예측의 경우 추세만으로도 우수한 예측 성능을 보이기도 한다(Lee et al., 2012). 하지만 열 또는 난방이 주목적인 도시가 스의 경우 온도의 영향은 절대적이라 할 수 있으며 요일에 의

† 연락저자 : 김윤배 교수, 660-701 경기 수원시 장안구 천천동 300 성균관대학교 시스템경영공학과 제2공학관 27415호, Tel : 031-290-7600, Fax : 031-290-7610, E-mail : kimyb@skku.edu

2012년 12월 26일 접수; 2013년 2월 7일 1차 수정본 접수; 2013년 4월 15일 2차 수정본 접수; 2013년 4월 29일 게재 확정. 
한 요인도 강하게 반영된다. 특히 일일수요의 시계열 자료의 추세적 요인을 설명하려면 요일에 의한 주기성(또는 계절성) 을 반드시 고려해야 한다. Lee et al.(2012)은 각 요일, 특히 주 말과 월요일의 전력에 특수한 패턴이 존재함을 설명하였다.

본 연구는 한국가스공사에서 제공하는 도시가스의 일일 총 수요를 예측하는 것을 목표로 한다. 이는 도시가스 일일수요 가 기존의 에너지 수요예측 모형들로는 설명하기 어렵기 때문 이다. 물론 기존의 널리 사용되는 누적자기회귀이동 평균(autoregressive integrated moving average, ARIMA) 모형이나 지수평 활법(exponential smoothing, ES) 등은 도시가스 일일수요를 비 교적 잘 설명한다. 그러나 이들도 공급자 측에서 요구하는 오 차율을 만족할 만한 성능을 보여주지는 못한다. 특히 이들은 특수한 계절이나 수요자 증가에 따른 수요량 급증 추세 등을 설명할 수 없었다. 따라서 본 연구에서는 평균오차율은 물론 오차의 분포 특성도 고려하여 우수한 예측성능을 보이는 모형 을 소개하고자 한다.

본 연구에서 모형 수립 및 검증을 위해 사용된 데이터는 KOGAS에서 제공한 2007년부터 2012년까지 약 6년간의 일일 공급량 실측자료이다. 앞서 언급한 바와 같이 본 연구에서 고 려한 수요결정 요인은 추세적 요인, 온도, 요일이다. 이들을 반 영하여 세 단계에 걸친 예측 모형을 개발한다. 본 연구에서 제 시하는 예측 모형은 1 년간의 수요예측에 있어 특정 시간에 편 향되지 않는 낮고 안정적적인 오차율을 보인다. 특히 ARIMA 나 ES 등과 같은 기존 모형들이 설명할 수 없었던 겨울철의 불 규칙적 수요와 주말수요를 분명하게 설명함으로써 보다 정확 한 예측을 수행할 수 있다. 또한 간단한 회귀 모형으로 접근함 으로써 사용자들의 이해가 쉽고 사용이 편리하다.

본 논문은 다음과 같이 구성되어 있다. 제 2장에서는 도시가 스 일일 공급량 데이터 분석을 통해 예측 모형에 필요한 요인 및 변수를 선정한다. 제 3 장에서는 본 연구에서 제시하는 도시 가스 일일 예측 모형에 대해 상세히 설명한다. 제 4장에서는 본 연구에서 제시하는 모형을 적용하여 예측을 수행하고 그 타당성을 확인하였다. 마지막으로 제 5 장에서는 본 연구의 결 론을 맺는다.

\section{2. 도시가스 일일 공급량 데이터 분석}

\section{1 도시가스 일일 공급량 실적 데이터}

본 논문에서는 한국가스공사의 2007년 1월 8일부터 2012년 11 월 31 일까지의 일일 공급량 데이터를 분석하였다. 도시가스 일일 공급량 패턴을 분석하기 위해 일일 열 공급량 변화를 $<$ Figure 1>에 나타내었다. <Figure 1>에서 보는 바와 같이 도시 가스의 일일 공급량은 해마다 일정한 추세와 주기성을 보인 다. 이는 계절적 수요특성이 반영된 결과라 할 수 있다. 그러나 연단위로 추세를 반영하기에는 모형이 복잡해지고 짧은 기간 에 나타나는 불규칙적인 추세를 반영하기 어렵다. 따라서 연
간 추세보다는 일간 추세를 적용하는 것이 더욱 타당하다고 판단된다.

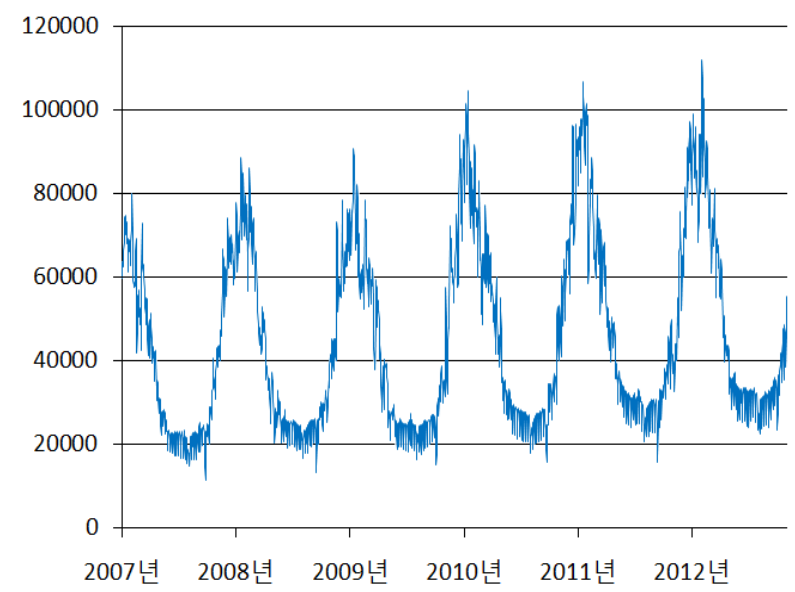

Figure 1. Change of city gas daily demand(from 2007 to 2012, ton)

일간 추세를 표현하기에 알맞은 방법은 일일 도시가스 공급 량을 시계열 관측 자료로 취급하여 자기회귀(autoregressive, $\mathrm{AR}$ ) 모형을 적용하는 것이다. 즉 예측되는 수요가 직전일의 공급량에 선형으로 비례하게 되는 것이다. <Figure 2>는 직전 일의 공급량과 당일의 공급량을 그린 산점도이다. <Figure 2> 에서 보는 바와 같이 두 공급량 사이에는 뚜렷한 선형이 나타 난다. 이는 결국 예측 모형에 AR 모형의 적용이 가능하다는 것 을 입증한다.

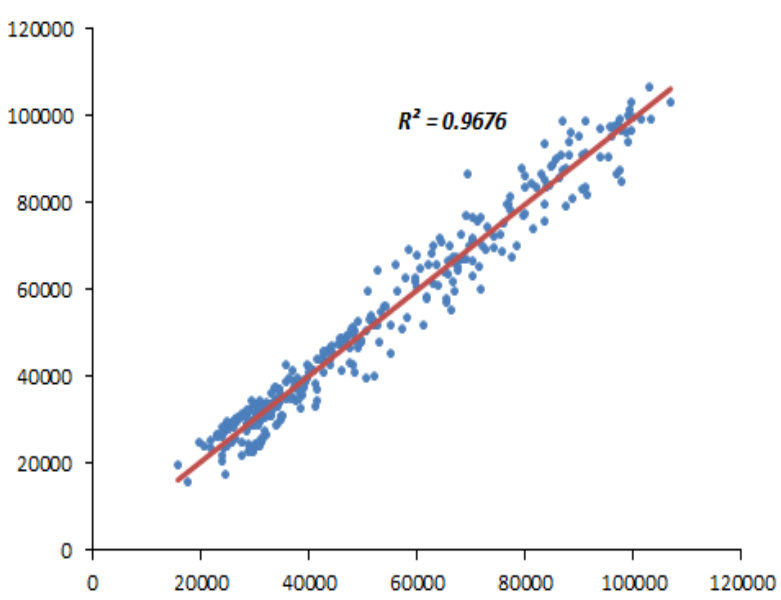

Figure 2. Linear relationship between successive daily demands

본 연구에서 제시하는 도시가스의 수요를 결정하는 또 하나 의 요인은 바로 온도이다. 온도와 일일 공급량의 관계를 규명 하기 위해 <Figure 3>을 보자. <Figure 3>의 횡축에 해당하는 온도는 해당일의 평균온도이다. <Figure $3>$ 에서 보는바와 같 이 공급량은 온도의 3 차 다항식으로 표현된다. 고차 다항식으 로 갈수록 결정계수 $\left(R^{2}\right)$ 가 높아지지만 그 정도가 미미하므로 본 연구에서는 3 차 다항식의 형태 유지하였다. 


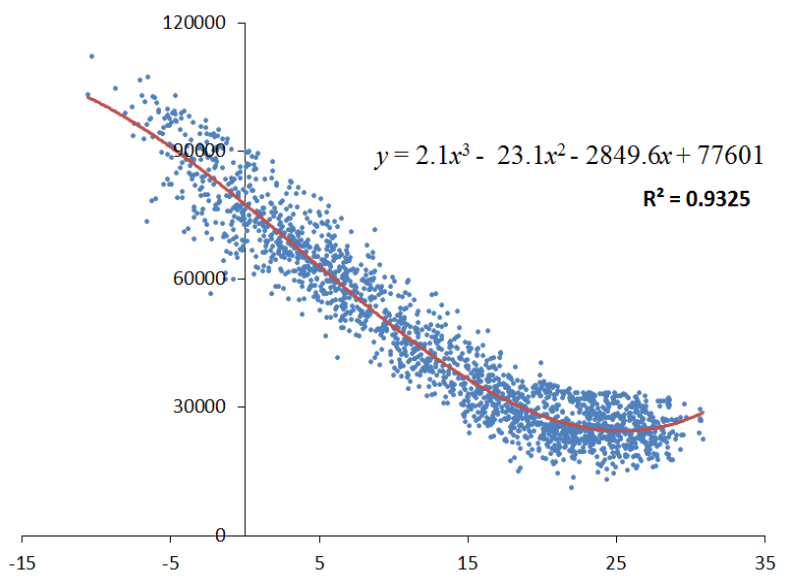

Figure 3. Polynomial relationship between mean outdoor temperature and daily demand

마지막으로 요일이 일일 공급량에 미치는 영향에 대해 살펴 본다. 요일을 반영하기 위해서는 시계열 자료에 계절성을 두 는 것이 가장 일반적이다. 특히 본 연구에서 실험해 본 결과 주 기가 7인 계절적 ARIMA 모형이 가장 적합하였고 예측성능도 우수한 편이었다. 그러나 ARIMA 모형도 앞서 언급한 바와 같 이 주말이나 겨울과 같은 날씨의 영향이 큰 계절에 대한 설명 력이 부족하여 도시가스 일일수요예측 모형으로는 부적합하 다고 판단하였다. 지수평활법의 경우도 역시 평균 $7 \%$ 이상의 오차율을 보여 공급자 측에서 요구하는 예측력을 만족시키지 못하므로 실제적인 사용이 부적합하였다. 따라서 본 논문에서 는 요일에 의한 요인을 앞서 살펴본 AR 모형과 온도 모형에 직 접 반영하는 방법을 사용하였다. 본 논문에서 사용한 방법은 각 모형에 대한 회귀계수를 요일별로 다르게 설정하는 방법으 로서 제 3장에서 상세히 설명하도록 한다.

\section{3. 도시가스 수요예측 모형의 개발}

본 장에서는 도시가스 일일 총수요를 예측하기 위한 수리적 모형을 전개한다. 본 논문에서 제시하는 모형은 통계적 기법 인 회귀분석과 가중평균법을 기반으로 하고 있어 모형의 이해 가 쉽고 사용이 용이하다는 장점이 있다.

\section{1 자기회귀 모형}

일일 총 도시가스 수요량 모형을 수식화하기 위해 편의상 날짜를 0 부터 시작하는 일련의 정수로 정의하자. 즉 모형결정 에 사용할 첫 번째 데이터에 해당하는 날짜를 0 으로 설정한다. 또한 $\mathrm{AR}$ 모형에 요일요인을 적용하기 위해 다음과 같은 변수 를 정의한다.

$Y_{t}$ : 날짜 $t$ 의 도시가스 총 수요량(또는 공급량)

$d_{t}$ : 날짜 $t$ 의 요일 $(1:$ 일요일, $7:$ 토요일 $)$

이를 이용하여 요일이 반영된 AR 모형은 다음 식 (1)과 같다.

$$
Y_{t}=\alpha_{d_{t}}+\beta_{d_{t}} Y_{t-1}+e_{t, d_{t}}
$$

여기서 $\alpha_{d_{t}}, \beta_{d_{t}}$ 는 각 요일별 회귀계수이고 $e_{t, d_{t}}$ 는 해당 요일의 오차 항으로 표현된다. 결국 식 (1)은 $d_{t}$ 의 값에 따라 총 7개의 요일별 회귀 모형으로 나뉘게 된다. 즉 날짜 $t$ 가 일요일인 경 우 다음의 식 (2)와 같은 형태를 띠게 된다.

$$
Y_{t}=\alpha_{1}+\beta_{1} Y_{t-1}+e_{t, 1}
$$

각각의 회귀계수들은 그 선 적합도인 결정계수가 매우 우수한 수준임을 확인하였다.

\section{2 온도 모형}

일일 도시가스 총 수요량 예측을 위한 또 하나의 요인은 바 로 온도이다. 앞서 언급한 바와 같이 온도 모형에도 요일의 적 용이 가능하다. 온도에 의한 수요결정 모형을 설명하기 위해 다음을 정의한다.

$X_{t}:$ 날짜 $t$ 의 총 도시가스 수요량 $\left(=Y_{t}\right)$

$T_{t}$ : 날짜 $t$ 의 평균온도

앞서 정의한 $d_{t}$ 를 이용하여 요일을 반영한 온도 모형을 정의 하면 다음과 같다.

$$
X_{t}=\tau_{0 d_{t}}+\tau_{1 d_{t}} T_{t}+\tau_{2 d_{t}} T_{t}^{2}+\tau_{3 d_{t}} T_{t}^{3}+e_{t, d_{t}}
$$

식 (3)에서 $\tau_{i d_{t}}$ 는 요일 및 차수별 계수이며, $e_{t, d_{t}}$ 는 역시 해당 요일의 오차 항을 나타낸다. 식 (3)으로부터 온도 모형의 경우도 총 7개의 회귀 모형을 얻을 수 있다. 여기서 온도 모형을 반영 함에 있어서 중요한 것은 시간에 따라 각 요일에 대한 계수들 이 바뀌게 된다는 것이다. 즉 도시가스의 수요는 <Figure 1>에 서와 같이 해가 지날수록 증가하는 추세를 보인다. 이러한 추 세는 온도 모형만으로는 설명하기가 어렵기 때문에 가장 최근의 데이터를 이용하여 회귀계수를 수정해 주어야 한다. 추세를 반영할 수 있는 방법은 앞서 설명한 수정된 AR 모형이다. 따라 서 온도 모형에 의한 결과에 추세를 적용한 결과를 적절히 혼 합하여 최종수요를 설명한다면 보다 정확한 예측이 가능할 것 이다. 이를 위해 본 논문에서는 수정된 $\mathrm{AR}$ 모형에 의한 예측 결과와 온도 모형 예측결과에 대한 가중평균 모형을 제안한다.

\section{3 가중평균 모형}

온도 모형에서 수요량을 수정된 $\mathrm{AR}$ 모형에서 사용한 $Y_{t}$ 가 아닌 $X_{t}$ 로 표기한 것은 제안 예측방법의 핵심인 가중평균 모 형을 설명하기 위함이다. 즉 온도 모형의 예측결과 $X_{t}$ 와 수정 된 $\mathrm{AR}$ 모형의 예측결과 $Y_{t}$ 에 가중평균을 주면 추세와 온도를 
동시에 반영할 수 있다. 가중평균에 의한 최종 수요 $Z_{t}$ 는 다음 과 같이 표현된다.

$$
Z_{t}=w_{t} \widehat{X}_{t}+\left(1-w_{t}\right) \widehat{Y}_{t}
$$

여기서 $\widehat{X}_{t}$ 와 $\widehat{Y}_{t}$ 는 각각 온도 모형과 수정된 $\mathrm{AR}$ 모형에 의한 수요의 추정치를 나타낸다. $w_{t}$ 는 가중치로서 날짜 $t$ 에 따라 변 하는 시계열이다.

수정된 AR 모형과 온도 모형의 계수들은 회귀분석을 통해 쉽게 구할 수 있다. 그러나 가중평균 모형의 경우 가중치가 해 당 날짜에 종속적이므로 식 (4)가 최적의 예측치를 낼 수 있도 록 $w_{t}$ 를 결정해주어야 한다. 본 논문에서는 최근 $n$ 일간의 상 대오차제곱합(sum of squared errors)을 최소화하여 식 (5)를 유 도하였다.

$$
w_{t}=\frac{\sum_{k=t-1}^{t-n} \frac{\left(Z_{k}-\widehat{Y}_{k}\right)\left(\widehat{X}_{k}-\widehat{Y}_{k}\right)}{Z_{k}^{2}}}{\sum_{k=t-1}^{t-n} \frac{\left(\widehat{X}_{k}-\widehat{Y}_{k}\right)^{2}}{Z_{k}^{2}}}
$$

식 (5)의 사용은 실제 예측에 있어 매우 우수한 성능을 보이 는데 이는 제 4장의 결과에서 확인할 수 있다. 여기서 중요한 것은 바로 $n$ 값에 따라 예측성능이 결정된다는 점이다. 따라 서 $n$ 값의 선택이 매우 중요하다. 본 논문에서는 경험적인 방 법을 통해 연간 평균절대백분율오차(mean absolute percentage error, MAPE)를 최소화하는 $n$ 값을 최적의 값으로 결정하였 다. 가중평균 모형은 $w_{t}$ 의 값이 음이거나 1 보다 큰 경우가 발 생하는데 이는 가중평균의 개념과는 거리가 있다. 이 경우, 음 에 대해서는 0,1 보다 큰 값에 대해서는 1 을 취하면 된다. 그러 나 가중치의 범위를 0 과 1 사이에 두지 않고 확장한다면 더욱 좋은 성능의 예측결과를 얻을 수도 있다.

\section{4 공휴일 모형}

기존 모형을 도시가스 일일수요에 적용할 수 없는 이유 중 하나가 바로 공휴일에 대한 예측 오차 때문이다. 공휴일의 경 우 해당 공휴일의 요일에 따라 그 수요의 패턴이 달라진다. 먼 저 공휴일이 주말일 경우는 일반적인 주말의 형태와 크게 달 라지지 않는데 이는 주 5 일제가 되어 발생하는 현상이라 볼 수 있다. 따라서 주말인 공휴일은 공휴일 모형에서 배제하였다.

공휴일에는 일반적으로 전날에 비해 수요량이 감소한다. 금 요일의 경우는 그 감소하는 정도가 더 커지는데 이는 잇따르 는 주말과 함께 연휴의 성격을 띠게 되기 때문이다. 월요일인 경우도 역시 연휴의 마지막 날이 되어 수요의 패턴이 달라진 다. 그러나 월요일의 경우는 연휴의 마지막 날이라는 특성상 다른 요일과는 매우 다른 양상을 보인다. 따라서 본 논문에서 는 월요일에 대한 공휴일 모형을 구분하였다. 공휴일 모형을
위해 다음과 같은 지시변수를 정의하자.

$$
F_{t}= \begin{cases}1 & (\text { if } t \text { is Friday }) \\ 0 & (o / w)\end{cases}
$$

이를 이용하여 화요일부터 금요일까지의 공휴일모형은 다 음과 같이 정의할 수 있다.

$$
Y_{t}=\alpha_{H}+\beta_{H} Y_{t-1}+\gamma_{H} F_{t}+\varepsilon_{t}
$$

또한 월요일의 공휴일 모형은 다음과 같다.

$$
Y_{t}=\alpha_{M}+\beta_{M} Y_{t-1}+\varepsilon_{t}
$$

식 (6)과 식 (7)에 의한 공휴일 모형은 가중평균이 적용되지 않는 독립적인 모형이다. 본 모형은 도시가스 일일 총수요에 대해 그 설명력이 매우 뛰어나다는 것을 적용 실험을 통해 확 인하였다.

\section{4. 모형 적용 결과 및 분석}

\section{1 예측 모형의 적용}

본 논문에서는 KOGAS의 일일 공급량 실측 데이터를 이용 하여 예측을 수행하였다. 2011년 10월 이전의 데이터를 이용 하여 각 모형의 회귀계수를 결정하고, 2011년 11월 1일부터 2012년 10월 31일까지의 일일수요를 예측하였다. 먼저 수정된 $\mathrm{AR}$ 모형과 온도 모형에 의해 각각의 수요 예측치를 구하고, 이 들을 가중평균하여 최종 예측수요를 결정하였다. 본 실험에서 결정된 가중평균 모형의 최적 $n$ 값은 4 이며 가중치의 범위에 제한을 두지 않았다.

\section{2 결과 분석}

2012년 10월 31 일을 기준으로 산출된 각 모형의 회귀계수들 은 <Table 1>과 <Table 2>에 정리한 바와 같다. 각 표에서 보는 바와 같이 그 결정계수들이 매우 높으므로 모든 모형의 설명 력이 매우 높다는 것을 확인할 수 있다.

<Figure 4>는 2012년 1월 1일부터 2012년 2월 29일까지의 실 제 관측치와 예측치를 시간의 순서에 따라 타점한 것이다. 이 는 겨울철로서 수요량이 가장 많을 때이며 예측력도 다른 기 간에 비해 떨어지는 기간이다. 그럼에도 불구하고 <Figure 4> 에서 보는 바와 같이 제안 모형에 의한 예측 결과는 실제 관측 치를 매우 정확히 묘사하고 있다. 특히 ARIMA와 지수평활법 등의 기존 모형들이 잘 설명할 수 없었던 주말이나 겨울철의 경우에도 예측결과가 실측치를 매우 잘 따라가는 것을 볼 수 있다. 그러나<Figure $4>$ 만으로는 제안 모형에 의한 예측 성능 을 정확히 측정할 수 없기 때문에 예측 오차에 대한 고찰이 필 요하다. 
Table 1. Regression coefficients of autoregressive model

\begin{tabular}{c|cc|c}
\hline 요일 & 상수 & 1일 전 수요 & 결정계수 \\
\hline 일 & -1647.20 & 0.96 & 0.9793 \\
월 & 5922.04 & 1.01 & 0.9834 \\
화 & 1704.63 & 0.99 & 0.9874 \\
수 & -514.95 & 1.01 & 0.9783 \\
목 & 840.91 & 1.00 & 0.9827 \\
금 & 464.85 & 0.98 & 0.9866 \\
토 & -2137.30 & 0.96 & 0.9910 \\
\hline
\end{tabular}

Table 2. Regression coefficients of temperature model

\begin{tabular}{c|cccc|c}
\hline 요일 & 상수 & 평균온도 온도 제곱 온도 세제곱 & 결정계수 \\
\hline 일 & 76721.70 & -2978.60 & 4.99 & 1.19 & 0.9769 \\
월 & 84821.18 & -3053.72 & -4.99 & 1.60 & 0.9713 \\
화 & 87430.10 & -3445.40 & 17.84 & 1.21 & 0.9787 \\
수 & 87058.80 & -2771.50 & -43.43 & 2.54 & 0.9821 \\
목 & 86273.10 & -2988.10 & -14.98 & 1.82 & 0.9840 \\
금 & 85757.70 & -2846.20 & -25.20 & 2.01 & 0.9806 \\
토 & 80680.10 & -2884.50 & -11.482 & 1.63 & 0.9880 \\
\hline
\end{tabular}

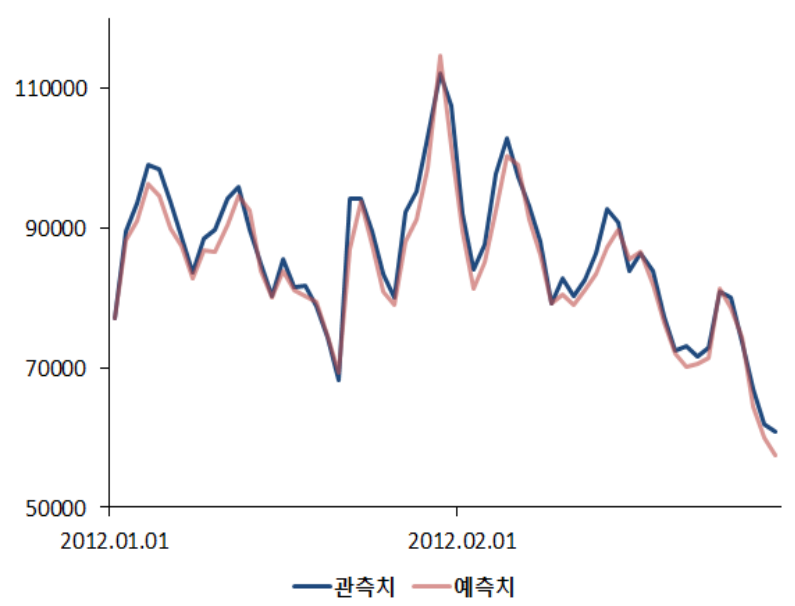

Figure 4. Observations vs. forecasted values for daily demand (from Jan. 1 to Feb. 29 in 2012)

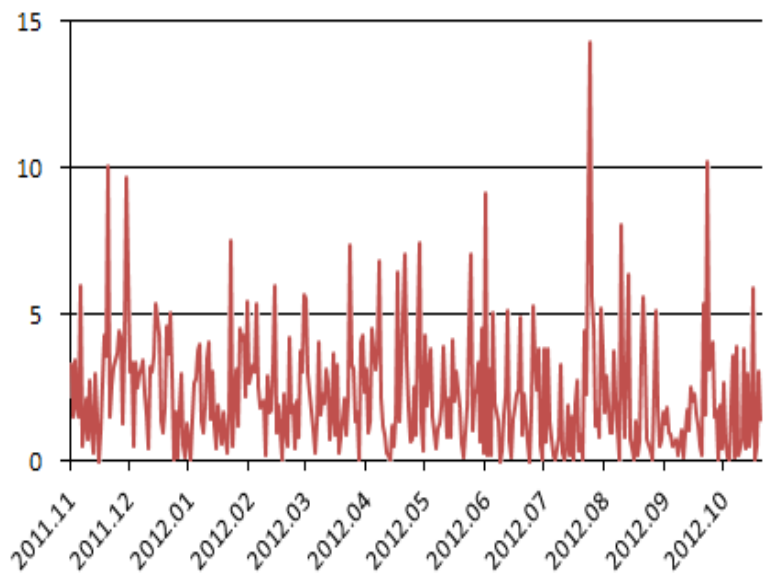

Figure 5. APEs of forecasted values for daily demand(from Nov. 12011 to Oct. 31 2012, \%)
본 실험에서는 예측의 정확도를 보다 자세히 관찰하기 위해 예 측된 일일수요량에 대한 실측치 대비 절대백분율오차(absolute percentage error, APE)를 계산하였다. <Figure 5>는 시간 에 따른 $\mathrm{APE}$ 를 그린 결과이다. <Figure $5>$ 는 특정 계절이나 달 에 편향되지 않는 안정적인 예측 성능을 보여준다. 즉 예측 오 차가 시간적 요인에 영향을 받지 않고 고르게 분포함을 알 수 있다.

$<$ Figure 6>은 1년간 APE들의 분포를 보다 정확히 살펴보기 위해 그린 상자도표(box plot)이다. <Figure 6>에서 비정상 관 측치로 보이는 APE 값은 최대값으로서 <Figure 5>의 7월 말, 정확히는 7 월 30 일의 값이다. 이 날은 폭염주의보가 내릴 만큼 무더웠으며 여름휴가가 절정에 이르렀을 때이다. 이러한 상황 에서도 첫날 단 하루를 제외하고는 이후 지속적으로 올바른 예측결과를 보이고 있다. 이는 가중평균 모형이 온도 모형에 의하여 반영되지 못하는 상황을 수정된 AR 모형이 설명할 수 있도록 AR모형의 가중치를 올려주기 때문이다.

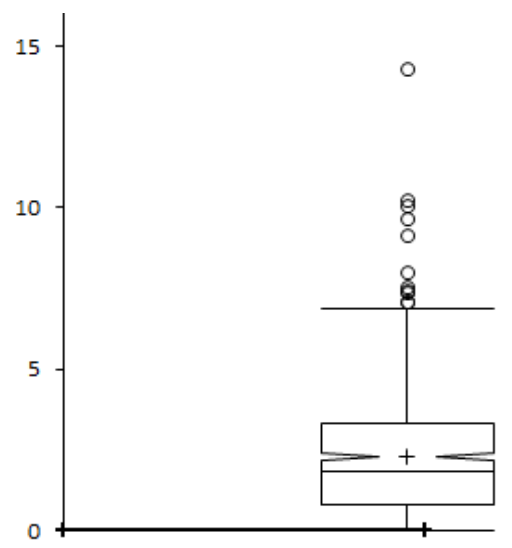

Figure 6. Box plot for APEs in $<$ Figure $5>(\%)$

마지막으로 본 연구에서는 동일한 실험조건 하에서 다양한 모형에 의한 예측을 수행하였다. ARIMA 모형의 경우 계절성을 갖는 $\operatorname{ARIMA}(1,1,0) \times(0,1,1)_{7}$ 모형이 가장 적합하였다. $<$ Table $3>$ 은 제안된 가중평균 모형과 ARIMA 모형, 그리고 지수평활 법에 의한 예측 결과의 $\mathrm{APE}$ 를 계산하여 그 통계량을 나열한 것이다. ARIMA나 ES의 경우 휴일, 주말 등의 특수한 날에 오 차율이 크게 나타났다. 반면에 자기회귀 모형과 온도 모형은 온도의 일변화에 따라 그 오차율의 크기가 변한다. 자기회귀 는 온도의 일변화가 큰 경우에 오차율이 증가하고 온도 모형 은 온도의 일변화가 거의 없고 균일할 때 그 오차율이 커진다. 이 때, 제안모형인 가중치 모형이 오차를 줄이는 역할을 한다.

$<$ Table 3>에서 보는 바와 같이 제안 모형의 예측력은 ARIMA 나 ES에 비해 월등하다. <Table $3>$ 의 백분위수는 예측의 정확 도를 표현 할 수 있는 통계량이다. 이들은 오차율의 분산을 대 신할 수 있는 통계량으로서 각 모형의 정확도를 비교 - 판단할 수 있다. 가령 제안 모형으로 예측된 일일수요의 $90 \%$ 이상이 실제 값에 대해 $5 \%$ 미만의 오차를 보인다고 할 수 있다. 이에 
Table 3. Comparison of statistics for APEs produced by various models

\begin{tabular}{cccccc}
\hline \multirow{2}{*}{ 통계량 } & \multicolumn{5}{c}{ 모형(단위 : \%) } \\
\cline { 2 - 6 } & $\begin{array}{c}\text { 자기 } \\
\text { 회귀 }\end{array}$ & $\begin{array}{c}\text { 온도 } \\
\text { 모형 }\end{array}$ & $\begin{array}{c}\text { 제안 } \\
\text { 모형 }\end{array}$ & ARIMA & ES \\
\hline 평균 & 3.59 & 7.03 & 2.40 & 3.95 & 7.39 \\
25 백분위 & 1.51 & 2.59 & 0.85 & 1.10 & 2.40 \\
중위수 & 3.67 & 5.73 & 1.90 & 2.58 & 5.62 \\
75 백분위 & 6.61 & 8.98 & 3.36 & 5.10 & 11.07 \\
90 백분위 & 7.86 & 12.49 & 4.52 & 8.74 & 16.30 \\
\hline 최대값 & 30.85 & 52.54 & 14.33 & 40.27 & 31.88 \\
\hline
\end{tabular}

반해 ARIMA의 성능은 평균적으로는 비교적 정확하지만 예측 오차의 분포에 있어서는 결과의 $75 \%$ 정도만이 $5 \%$ 이내의 예 측 오차를 보임을 판단할 수 있다. $\mathrm{ES}$ 의 경우 그 예측력이 온 도 모형과 유사하며 다른 모형들에 비해 성능이 상대적으로 열등함을 확인할 수 있다.

\section{5. 결 론}

본 논문은 도시가스 일일수요를 추세, 온도, 요일의 세 가지 요 인에 의해 예측하는 방법을 제안하였다. 추세적 요인은 AR 모 형을, 온도 모형은 비선형 회귀 모형을 사용하여 반영하였다. 요일요인은 이들 모형에 직접 반영함으로써 각각 7 개의 모형 으로 세분화시켰다. 또한 실제 수요를 보다 정확히 설명하기 위해 수정된 $\mathrm{AR}$ 모형과 온도 모형의 가중평균 모형을 사용하 였다. 제안 모형을 실제 사례에 적용한 결과 매우 우수한 성능 을 보임을 검증하였으며, ARIMA 모형에 의한 결과와의 비교 를 통해 본 논문에서 제안하는 예측 방법의 우월성을 확인하 였다.

본 모형은 명절과 명절 전, 후일, 그리고 급작스런 온도변화 에 비교적 높은 오차율을 보였다. 명절이 있는 주의 수요 패턴 은 평일이라도 다른 주의 평일 수요 패턴과 매우 다르다. 또한 환절기의 온도의 변화는 체감온도의 급상승 또는 급하강을 유 도하게 되므로 수요 패턴이 변하게 된다. 따라서 명절에 관련 된 모형을 추가로 개발하고 제안된 모형을 온도의 변화에 민 감한 모형으로 발전시켜야 할 것이다. 온도 모형의 독립변수 로서 실제온도가 아닌 체감온도를 사용하는 것도 예측력을 높 이는 하나의 방법일 것이다. 만일 이러한 다수의 입력 자료를 이용하게 된다면 이에 합당한 신경망 모형을 개발하는 것도 시도해 볼 만한 연구가 될 것이라 사료된다.

\section{참고문헌}

Amina, M., Kodogiannis, V. S., Petrounias, I., and Tomtsis, D. (2012), A hy- brid intelligent approach for the prediction of electricity consumption, International Journal of Electrical Power and Energy Systems, 43(1), $99-108$.

Azadeh, A., Asadzadeh, S. M., and Shanbari, A. (2010), An adaptive network-based fuzzy infrerence system for short-term natural gas demand estimation : Uncertain and complex environments, Energy Policy, 38(3), 1529-1536.

Baczyński, D. and Parol, M. (2004), Influence of artificial neural network structure on quality of short-term electric energy consumption forecast, IEE Proceedings-Generation, Transmission and Distribution, 151(2), 241-245.

Baek, J.-K. and Han, J.-H. (2011), Forecasting of Heat Demand in Winter Using Linear Regression Models for Korea District Heating Corporation, Journal of the Korea Academia-Industrial Cooperation Society, 12(3), 1488-1494.

Brown, R. H. and Matin, L. (1995), Development of artificial neural-network models to predict daily gas consumption, Proceedings of the 1995 IEEE IECON $21^{\text {st }}$ International Conference on Industrial Electronics, Control, and Instrumentation, 1389-1394.

Cheng, Y., Luh, P. B., Guan, C., Zhao, Y., Michel, L. D., Coolbeth, M. A., Friedland, P. B., and Rourke, S.J., Short-Term Load Forecasting : Similar Day-Based Wavelet Neural Networks, IEEE Transactions on Power Systems, 25(1), 322-330.

Chramcov, B. (2010), Heat demand forecasting for concrete district heating system, International Journal of Mathematical Models and Methods in Applied Sciences, 4(4), 231-239.

Dotzauer, E. (2002), Simple model for prediction of loads in district-heating systems, Journal of Applied Energy, 73(3/4), 277-284.

Erdogdu, E. (2010), Natural gas demand in Turkey, Applied Energy, 97(1), 211-219.

Hippert, H. S., Pedreira, C. E., and Souza, R. C. (2001), Neural networks for short-term load forecasting : a review and evaluation, Journal of IEEE Transactions on Power Systems, 16(1), 45-55.

Kim, J.-S., Yang, C.-S., and Park, J.-G. (2011), An Empirical Study on the Consumption Function of Korean Natural Gas for City Gas, Journal of Energy Engineering, 20(4), 318-329.

Kvarnsöm, J., Liljedahl, J., and Dotzauer, E. (2006), Forward temperatures and production planning in district heating systems, 10th International Symposium on District Heating and Cooling, 1-6.

Lee, B. C., Park, J., and Kim, Y. B. (2012), A New Trend Based Approach for Forecasting of Electricity Demand in Korea, International Journal of Industrial Engineering-Theory, Application and Practice, 19(1), 47-56.

Li, J., Dong, X, Shangguan, J., and Hook, M. (2011), Forecasting the growth of China's natural gas consumption, Energy, 36, 1380-1385.

Ling, S. H., Leung F. H. F., Lam, H. K., and Tam, P. K. S. (2003), Short-Term Electric Load Forecasting Based on a Neural Fuzzy Network, IEEE Transactions on Industrial Electronics, 50(6), 1305-1316.

Park, T. C., Kim, U. S., Kim, L. H., Kim, W. H. and Yeo, Y. K. (2009), Optimization of district heating systems based on the demand forecast in the capital region, Korean Journal of Chemical Engineering, 26(6), 1484-1496.

Sarak, H. and Satman, A. (2003), The degree-day method to estimate the residential heating natural gas consumption in Turkey : a case study, Energy, 28, 929-939.

Song, K. B., Park, J., Kim, Y. B., and Jung, C. W. (2011), Heat Demand Forecasting for Local District Heating, IE Interfaces, 24(4), 373-378.

Wadud, Z., Dey, H. S., Kabir, M. A., and Khan, S. I. (2011), Modeling and forecasting natural gas demand in Bangladesh, Energy Plicy, 39(11), $7372-7380$. 